\title{
Depletion of predatory fish by fishing in a temperate reef ecosystem leads to indirect effects on prey, but not to lower trophic levels
}

\author{
Kylie Cook $^{1,2, *}$, Mathew A. Vanderklift ${ }^{2}$ \\ ${ }^{1}$ The University of Western Australia, Crawley, Western Australia 6009, Australia \\ ${ }^{2}$ CSIRO Marine and Atmospheric Research, Wembley, Western Australia 6913, Australia
}

\begin{abstract}
Indirect effects of fishing extending 2 or more trophic levels have been observed in a range of ecosystems, but they are not ubiquitously present, and identifying the circumstances in which they occur (or do not occur) is a key challenge for ecologists. We compared a fully protected sanctuary (no fishing allowed) with 2 other types of management zones (one in which all types of fishing were allowed and another in which only recreational line fishing was allowed) at Rottnest Island, Australia. We predicted that fishing would result in lower abundance of predatory fish in the 2 fished zones. We further predicted that, if indirect effects of fishing are important, there would be lower predation on sea urchins and turbinid gastropods, higher abundance of these herbivorous invertebrates and lower biomass of macroalgae in both types of fished zones. The abundance of predatory fish and predation on the sea urchin Heliocidaris erythrogramma were higher in the sanctuary than in fished zones. Predation on the sea urchin Centrostephanus tenuispinus was higher and densities of $H$. erythrogramma were lower in the sanctuary, but the magnitude of the difference in these measures (and, therefore, the results of statistical tests) was variable among years. However, predation on turbinid gastropods, densities of C. tenuispinus and turbinid gastropods, and the biomass of macroalgae did not differ significantly among management zones. The pattern of higher abundance of predatory fish and higher rates at which prey were consumed in the sanctuary provide evidence for the indirect effects of fishing on the abundance of $H$. erythrogramma. However, there was no evidence that these indirect effects extend to a second species of sea urchin, or to turbinid gastropods, and no evidence that the effects lead to broad changes in the state of the ecosystem.
\end{abstract}

KEY WORDS: Kelp $\cdot$ Marine protected area $\cdot$ Predation $\cdot$ Tethering experiment $\cdot$ Top-down control

\section{INTRODUCTION}

Predators can exert a profound influence on the structure of ecosystems - an influence that includes limiting the abundance of their prey (top-down control; e.g. Hairston et al. 1960, Polis 1994). In some circumstances, alterations in the abundance of a predator result in a pattern of alternating high and low abundances at successively lower trophic levels, a phenomenon known as a trophic cascade (Paine 1980). However, this phenomenon is not ubiquitous in nature, so understanding the circumstances in which predators exert a strong influence is crucial for managers of nat- ural resources (Shears et al. 2008). Hairston et al. (1960) proposed that predators will generally exert a strong influence on their prey in communities with discrete autotroph, herbivore and predator trophic levels. This theory was extended to propose that communities with an uneven number of trophic levels (i.e. 3, 5 and so on) should be strongly influenced by predators whereas those with an even number of trophic levels (i.e. 2, 4 and so on) should be determined by productivity of autotrophs (Fretwell 1987).

One criticism of the theory is that trophic relationships are rarely ordered into discrete trophic levels, and omnivory is ubiquitous - these observations sug- 
gest that trophic cascades are likely to be uncommon (Polis 1994, Bascompte et al. 2005). Nevertheless, the theory provides a useful framework from which hypotheses can be developed (and tested) about patterns of abundance at alternating trophic levels. Such hypotheses have been tested in multiple ecosystems. Some of the clearest examples of trophic cascades have been provided by such studies in ecosystems with sea urchins as the dominant herbivore. These examples encompass marine ecosystems from temperate kelp forests (e.g. Shears \& Babcock 2002, Estes et al. 2004) to tropical coral reefs (e.g. McClanahan et al. 1999). Inferences derived from these studies are typically generated from contrasting places that have abundant predators of sea urchins with places that do not. A commonly observed pattern is that where predators are abundant, abundances of sea urchins are low and abundances of benthic macroalgae (such as kelp) are high. Conversely, where predators are scarce, sea urchins can be very abundant, resulting in high rates of grazing on benthic macroalgae, which in turn can result in dramatic changes that propagate through the ecosystem (Babcock et al. 1999, Micheli et al. 2005). The primary inference from these spatial contrasts is that reductions in the abundance of predators (through hunting or fishing) result in changes in abundance at lower trophic levels. However, inverse patterns of abundance between predators, sea urchins and macroalgae are not ubiquitous, and reductions in abundance of predators do not always lead to increases in abundance of sea urchins or reductions in the abundance of macroalgae (Dayton et al. 1998, Foster \& Schiel 2010).

Strong evidence for indirect effects of fishing typically exists from places where there is an obvious difference in the abundance of the dominant autotrophs, such that alternate ecosystem states are clearly visible-such as kelp forests versus encrusting coralline algae barrens (e.g. Steneck et al. 2002). However, the evidence for indirect effects in ecosystems where this dichotomy does not exist is more equivocal (e.g. Sala et al. 1998, Connell 2007). The absence of a clear dichotomy of alternate states, however, does not mean that indirect effects of predators are not present, but might instead reflect that there are other processes that also strongly influence the abundance of the dominant autotrophs.

Although there are numerous studies that contrast abundances of different trophic levels at places that have experienced different intensities of hunting or fishing, few studies have quantified and contrasted rates of predation (but see Shears \& Babcock 2002, Hereu et al. 2005, Pederson \& Johnson 2006, Ling et al. 2009). Although the approach of comparing places with different intensities of hunting or fishing can provide circum- stantial evidence that trophic cascades exist, quantification of rates of predation provides a much stronger basis for inferences about the effects of predators.

Spatial comparisons alone do not yield inferences that are as robust as studies that also document temporal changes, but they do have value in situations where no information exists for pre-exploitation (or preconservation) abundances. Insights from marine protected areas (MPAs) that prohibit or limit fishing have been particularly useful. However, MPAs often vary in the fishing activities that they manage, and the degree to which this influences abundances of predators (and their prey) is not well understood. For example, there are indications that partially protected areas, such as those that prohibit commercial fishing but allow recreational fishing, do not result in the same changes in predator abundance as fully protected areas (Denny \& Babcock 2004).

Several studies of temperate reef ecosystems in eastern Australasia have concluded that predators control abundances of sea urchins (e.g. Tasmania: Pederson \& Johnson 2006, Ling et al. 2009; or New Zealand: Babcock et al. 1999, Shears \& Babcock 2002, Shears \& Babcock 2003). However, temperate reefs of western and eastern Australia differ in the overall abundances of sea urchins (Fowler-Walker \& Connell 2002, Vanderklift \& Kendrick 2004) and in the structure of stands of canopy algae (Connell \& Irving 2008). Although abundances of sea urchins are typically low, they can attain high densities in some places (Vanderklift \& Kendrick 2004), but even in those places their influence appears to be minor because they mainly eat drift algae (Vanderklift \& Kendrick 2005). These observations have led to the suggestion that the combination of generally low abundances of sea urchins and a reliance on drift algae will mean that the indirect effects of fishing on the abundance of kelp will not be evident in southern and western Australia (Connell 2007, Connell \& Irving 2008, 2009).

In the present study, we tested questions arising from the general framework of trophic cascades. We compared management zones at Rottnest Island (Australia) in which fishing is regulated to assess whether these zones have different abundances of predatory fish that would be consistent with direct effects of fishing, and different abundances of large herbivorous invertebrates and macroalgae that would be consistent with indirect effects of fishing mediated through predatory fish. We asked the following questions: (1) is the density of predatory fish higher in a sanctuary where fishing is prohibited than in adjacent zones where fishing is allowed ${ }_{i}(2)$ are relative rates of predation on sea urchins and herbivorous gastropods higher where fishing is prohibited; (3) is there a lower density of sea urchins and herbivorous gastropods where fish- 
ing is prohibited; and (4) is biomass of macroalgae greater where fishing is prohibited? Affirmative answers to the first 3 questions would support the inference that fishing has indirect effects on large invertebrates, whereas affirmative answers to all questions would suggest that fishing has cascading effects extending to macroalgae. Negative answers to at least 2 questions would mean that fishing does not have indirect effects.

\section{MATERIALS AND METHODS}

Study location. This study was carried out at Rottnest Island, Australia (32.1 $\left.{ }^{\circ} \mathrm{S}, 115.4^{\circ} \mathrm{E}\right)$ (Fig. 1). Rottnest Island is surrounded by patches of high-relief limestone reef interspersed with sand and seagrass meadows. Reefs are dominated by macroalgae, with the large brown algae Ecklonia radiata and Sargassum spp. forming canopies in some places. We focused our study around the 126 ha Kingston Reef Sanctuary Zone (SZ), which was established in 1988 and is enforced by the Rottnest Island Authority. Reefs inside the SZ host greater abundances, and larger individuals, of several species of fishes and the western rock lobster Panulirus cygnus than adjacent fished areas (Babcock et al. 2007, Kleczkowski et al. 2008).

Experimental design. Study sites contained high-relief reefs in 6 to $12 \mathrm{~m}$ depths located in 3 management zones: the SZ (no fishing permitted), the Recreation Zone (RZ: recreational line fishing permitted but commercial fishing and amateur net fishing not permitted) and General Use Waters (GUW: no fishing restriction other than statutory catch and size limits). Depth did not vary consistently among management zones ( $t$-test of maximum depths recorded by divers, $p>0.4$ ). Sites were generally separated by seagrass or sand, but in some cases were part of continuous reef habitat, and were separated by a minimum distance of $200 \mathrm{~m}$. In the austral summer 2004-2005 (November 2004-January 2005), measurements were taken at 12 sites: 6 in the SZ and 6 in the nearby RZ. The following summer (October 2005-March 2006), surveys were expanded to include a total of 30 sites, including all sites from 2004-2005 (see Fig. 1) plus an additional 6 sites in the RZ and 12 in the GUW. Sites were grouped in pairs (each pair is hereafter termed an 'area') to allow an assessment of variability at different spatial scales.

Data collection. Density of predatory fish: At each site, the density of predatory fish was quantified with underwater visual census (UVC). Three $50 \times 10 \mathrm{~m}$ transects were swum by SCUBA divers, recording counts of species known to be predators of sea urchins (identities of these species are listed in the Results). Predatory species were identified by opportunistic sightings of predation on tethered or untethered sea urchins by divers and video observations of predation on tethered sea urchins. Only species observed to be capable of successfully attacking and consuming a healthy, living sea urchin were considered predators (scavengers were not included).

Rates of predation: To determine relative rates of predation, tethering experiments were conducted at 12 sites in 2004-2005 and at 18 sites in 2005-2006

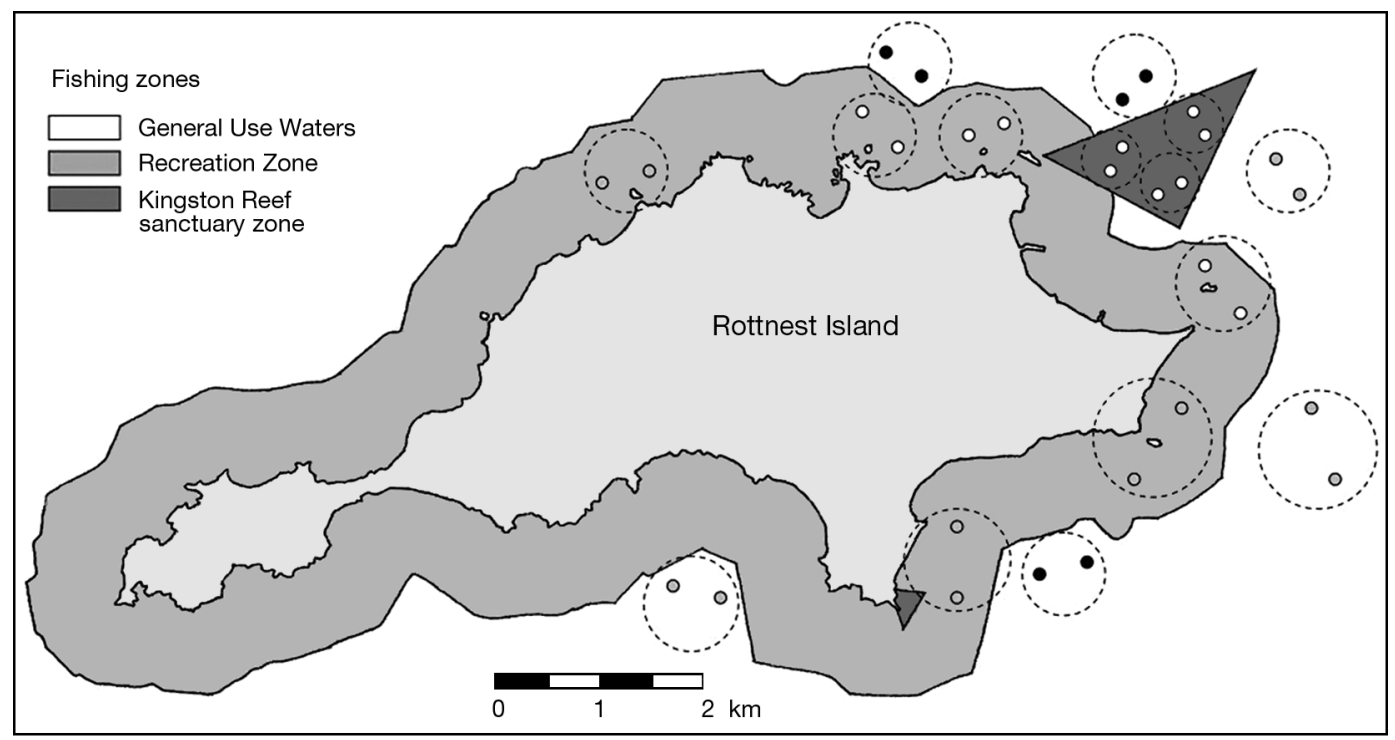

Fig. 1. Rottnest Island showing fishing zones (General Use Waters, Recreation Zone and Kingston Reef Sanctuary Zone, as indicated by shading), areas (indicated by dashed circles) and study sites (dots). o: tethering experiments and abundance measures were undertaken in both years; •: tethering experiments and abundance measures were undertaken only in 2005-2006; 0: abundance measures (but not tethering experiments) were undertaken only in 2005-2006 
(Fig. 1) on different days to the UVC (to avoid possible influences on measurements of fish density). At each site, 2 common species of sea urchins (Heliocidaris erythrogramma, size range 12-92 $\mathrm{mm}$ test diameter, and Centrostephanus tenuispinus, 41-129 mm) were tethered. Herbivorous gastropods (a mixture of Turbo intercostalis and T. torquatus, 11-55 mm maximum shell dimension) were also included in 2005-2006. Either 8 (in 2004-2005) or 5 (in 2005-2006) of each of H. erythrogramma, C. tenuispinus and Turbo spp. were tethered at each site. Sea urchins were tethered by passing a needle (Terumo spinal needle, $30 \mathrm{~mm} \times$ 20 gauge) through the test (Shears \& Babcock 2002). Gastropods were tethered by drilling a small hole through the lip of the shell and then threading monofilament line through the hole. The line $(\sim 30 \mathrm{~cm}$ in length) was secured to a numbered clothes peg which was then pegged to a length of chain placed on the substrate. Tethered individuals were placed in areas of high-relief limestone reef where no canopy of macroalgae was present, and were positioned so they were able to grip the substrate but were unable to move close to each other, to prevent them from aggregating. Tethered individuals were retrieved after 22-24 h. On retrieval, the survival, presence of broken test or complete consumption of animal (loop of line remaining, indicating the animal was completely eaten), or indeterminate fate (line snapped or untied, fate of tethered animal uncertain) was recorded.

In 2005-2006, 5 additional Heliocidaris erythrogramma at each site were tethered to timing devices to determine whether nocturnal predators contributed to predation. For these, 2 additional piercings were made in the test for monofilament line that acted as stays, keeping tension on the line to the timing device. Timing devices were adapted from the chronographic tethering device used by Oliver et al. (2005) and consisted of sports stopwatches fitted with glass reed switches allowing remote activation by a $3 \times 5 \mathrm{~mm}$ ferrite disc magnet. Stopwatches were cast in polyester resin and fixed to a weighted backing board. A PVC disc, with magnet attached, was mounted onto this board and attached to the tether line so that, when pulled, the magnet passed across the switch and activated the stopwatch (Fig. 2), allowing the time of predation to be calculated.

Laboratory trials testing for tethering-induced mortality in Heliocidaris erythrogramma (with single piercing $\mathrm{n}=11$, with 2 additional piercings $\mathrm{n}=11$, size range 44-82 mm), Centrostephanus tenuispinus ( $\mathrm{n}=$ 12, size range $85-117 \mathrm{~mm}$ ) and Turbo torquatus $(\mathrm{n}=4$, size range $42-49 \mathrm{~mm}$ ) yielded zero mortality or signs of stress after $24 \mathrm{~h}$; we infer from this that tetheringinduced mortality was negligible for the duration of our field experiments (24 h). Although tethering can increase mortality rates, such experiments can still be used to compare relative mortality rates among different animals or treatments as long as the tether bias is constant among groups to be compared (see Peterson \& Black 1994 for a review).

Density of invertebrates and biomass of macroalgae: The density of large herbivorous invertebrates (sea urchins and gastropods) was assessed by divers searching 5 haphazardly placed $5 \times 1 \mathrm{~m}$ transects at each site. The biomass of macroalgae was quantified by removing all algae from 5 replicate $0.25 \mathrm{~m}^{2}$ quadrats at each site (in 2005-2006 only), sorting the algae into 5 groups (red algae, brown algae, green algae, Ecklonia radiate and Sargassum spp.) and weighing (wet mass) to the nearest gram.

Data analysis. The density of predatory fish and large herbivorous invertebrates and the biomass of macroalgae were analysed using a mixed-effects ANOVA, testing for differences among management zones (fixed factor with 3 levels: SZ, RZ and GUW), areas (random and nested in management zones) and sites (random and nested in areas). Data from each year were analysed separately. For 2005-2006, treatment sum of squares (SS) of the among-zone comparison was decomposed into 2 components according to Winer (1971) to follow an a priori planned set of comparisons: RZ vs. GUW and fished (RZ and GUW) vs. SZ. Because the interest in the area term was primarily to estimate the magnitude of variation at spatial scales of hundreds of metres, we pooled this source of variation with the site term whenever it was not statistically significant at $p>0.25$. Prior to analyses, densities of invertebrates and biomasses of macroalgae were log-transformed to conform to assumptions of heteroscedasticity and normality.

Survival of tethered sea urchins and gastropods was analysed using logistic regression, testing for differ-

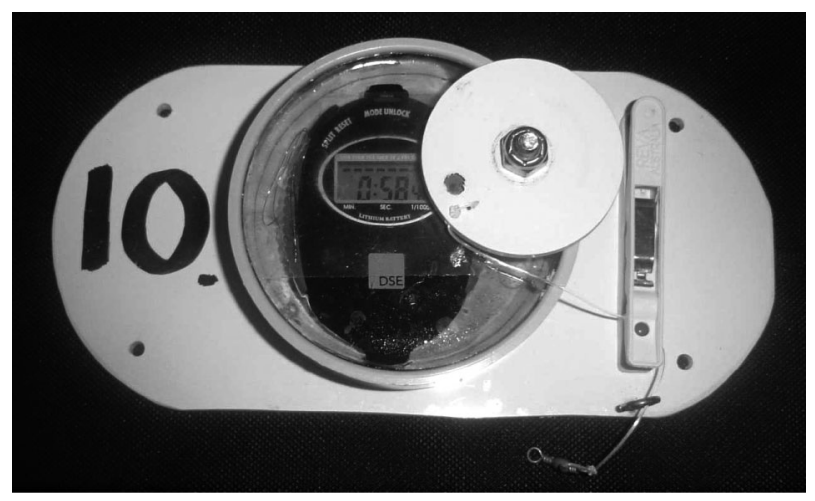

Fig. 2. The timing device used in this study. Heliocidaris erythrogramma were tethered to the device in order to obtain exact times of predation on tethered individuals 
ences in survival among management zones, areas and sites, as well as variation in mortality due to size. Instances where the fate of the animal was unknown were excluded from analysis. We were most interested in testing whether coefficients for each of the factors were statistically significant, so we focused on the significance of the deviances, tested using a $\chi^{2}$ test (Hosmer \& Lemeshow 2000). Odds ratios were calculated as $\left[\mathrm{p}_{1} /\left(1-\mathrm{p}_{1}\right)\right] /\left[\mathrm{p}_{2} /\left(1-\mathrm{p}_{2}\right)\right]$, where $\mathrm{p}_{1}$ is the proportion eaten by predators in the $\mathrm{SZ}$ and $\mathrm{p}_{2}$ is the proportion eaten by predators in the RZ and GUW (Hosmer \& Lemeshow 2000).

\section{RESULTS}

\section{Density of predatory fish}

Five species of fishes were observed to prey on adult Heliocidaris erythrogramma (size ranges of individuals seen at Rottnest Island given in parentheses): bluelined leatherjacket Meuschenia galii (15-40 cm), male brown-spotted wrasse Notolabrus parilus (20-35 cm), male western king wrasse Coris auricularis $(20-40 \mathrm{~cm})$, western foxfish Bodianus frenchii (10-45 cm) and western blue groper Achoerodus gouldii (35-100 cm). Only A. gouldii was observed to prey successfully on adult Centrostephanus tenuispinus. The 5 species were pooled for analysis; for N. parilus and $C$. auricularis only terminal phase males were included. Densities of these predatory fish were significantly higher in the SZ in both years (Table 1, Fig. 3). In 2004-2005, a mean $( \pm \mathrm{SE})$ of $3.00 \pm 0.43$ ind. $500 \mathrm{~m}^{-2}$ was recorded in the $\mathrm{SZ}$, compared with $1.00 \pm 0.41$ ind. $500 \mathrm{~m}^{-2}$ at fished sites. In 2005-2006, a similar pattern

Table 1. Mixed effects ANOVAs on counts of predatory fish, testing for differences among reefs in zones designed to manage different types of fishing. GUW: general use waters; RZ: recreation zone; SZ: Kingston Reef Sanctuary Zone. Values in bold are significant at $\alpha=0.05$

\begin{tabular}{|c|c|c|c|c|}
\hline Source of variation & $\mathrm{df}$ & MS & $F$ & $\mathrm{P}$ \\
\hline \multicolumn{5}{|l|}{ 2004-2005 } \\
\hline Fishing zone & 1 & 20.25 & 8.66 & 0.015 \\
\hline Area (Fishing zone) & Pooled & & & \\
\hline Site (Area, Fishing zone) & 10 & 2.34 & 0.68 & 0.733 \\
\hline Residual & 24 & 3.44 & & \\
\hline \multicolumn{5}{|l|}{ 2005-2006 } \\
\hline Fishing & 2 & 37.19 & 4.09 & 0.044 \\
\hline SZ vs. Fished & 1 & 49.88 & 5.49 & 0.037 \\
\hline RZ vs. GUW & 1 & 24.50 & 2.69 & 0.127 \\
\hline Area (Fishing zone) & 12 & 9.09 & 2.34 & 0.061 \\
\hline Site (Area, Fishing zone) & 15 & 3.88 & 2.93 & 0.001 \\
\hline Residual & 60 & 1.32 & & \\
\hline
\end{tabular}

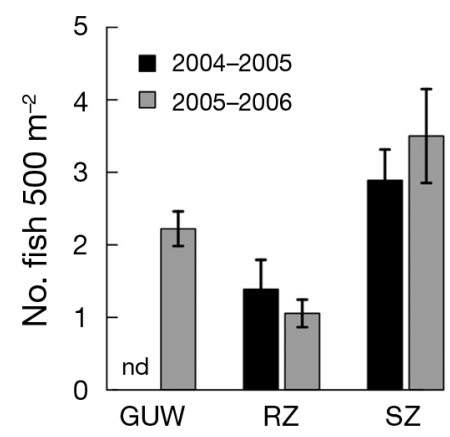

Fig. 3. Number of predatory fish seen on underwater visual census transects in the 3 fishing zones: general use waters (GUW), recreation zone (RZ) and Kingston Reef Sanctuary Zone (SZ). GUW were not sampled in 2004-2005. Predators were 5 species of fish known to prey on tethered sea urchins at the study sites. Mean $\pm \mathrm{SE}$, nd: no data

was observed $(3.50 \pm 0.64$ in the $\mathrm{SZ}, 1.64 \pm 0.17$ at fished sites). There were no differences in the abundance of predatory fish between the RZ and GUW ( $p$ > 0.12 , Table 1).

\section{Predation on tethered sea urchins}

Survival of tethered Heliocidaris erythrogramma was significantly lower in the SZ in both years (Fig. 4, Table 2). In 2004, H. erythrogramma placed in the SZ were 2.4 times more likely to be eaten than those placed outside; in 2005, $H$. erythrogramma placed in the SZ were 3.5 times more likely to be eaten. Sea urchin size had no effect on survival in 2004, but was a statistically significant influence in 2005 (Table 2): there was a significant decrease in survival with increasing size. Of the $H$. erythrogramma tethered to timing devices, 63 individuals showed evidence of being consumed by predators, with 14 timers (22\%) being successfully activated. In one instance, the timer had become entangled in drift algae, and so was

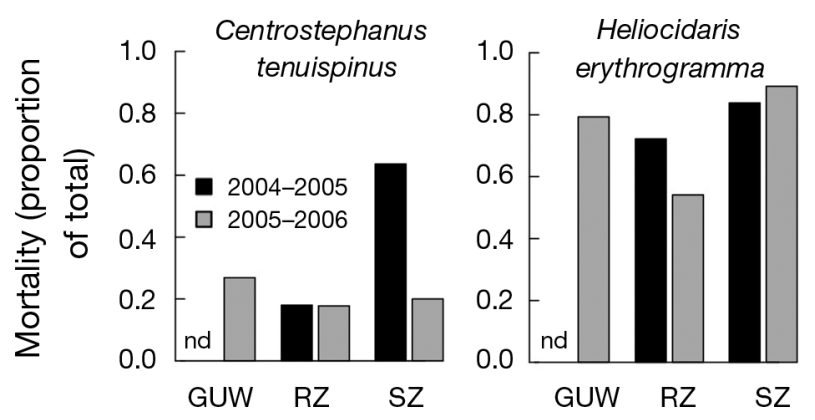

Fig. 4. Mortality of tethered sea urchins over $24 \mathrm{~h}$ in the 3 fishing zones. For abbreviations see Fig. 3, legend 
Table 2. Logistic regression testing for difference in survival of tethered sea urchins. Values in bold are significant at $\alpha=0.05$

\begin{tabular}{|lrrrrrrr|}
\hline \multirow{2}{*}{ Source of variation } & \multicolumn{3}{c}{ C. tenuispinus } & \multicolumn{3}{c|}{ H. erythrogramma } \\
& df & Deviance & $\mathrm{p}$ & df & Deviance & $\mathrm{p}$ \\
\hline $\mathbf{2 0 0 4 - 2 0 0 5}$ & & & & & & & \\
Urchin diameter & 1 & 2.54 & 0.111 & 1 & 0.03 & 0.870 \\
Fishing zone & 1 & 21.03 & $\mathbf{< 0 . 0 0 1}$ & 1 & 5.51 & $\mathbf{0 . 0 1 9}$ \\
Area (Fishing zone) & 4 & 15.96 & $\mathbf{0 . 0 0 3}$ & 4 & 18.66 & $<\mathbf{0 . 0 0 1}$ \\
Site (Area, Fishing zone) & 6 & 35.34 & $\mathbf{< 0 . 0 0 1}$ & 6 & 24.40 & $<\mathbf{0 . 0 0 1}$ \\
Error & 92 & 67.92 & 0.972 & 99 & 96.19 & 0.561 \\
2005-2006 & & & & & & \\
Urchin diameter & 1 & 2.85 & 0.091 & 1 & 5.57 & $\mathbf{0 . 0 1 8}$ \\
Fishing zone & 2 & 0.534 & 0.766 & 2 & 6.74 & $\mathbf{0 . 0 3 4}$ \\
Area (Fishing zone) & 6 & 11.70 & 0.067 & 6 & 20.93 & $\mathbf{0 . 0 0 2}$ \\
Site (Area, Fishing zone) & 8 & 25.62 & $\mathbf{0 . 0 0 2}$ & 8 & 12.27 & 0.139 \\
Error & 65 & 46.58 & 0.959 & 63 & 45.02 & 0.958 \\
& & & & & & & \\
\hline
\end{tabular}

aquaria over 4 consecutive days $(\mathrm{n}=32$ H. erythrogramma in total). No sea urchins were consumed by any lobsters.

\section{Density of herbivorous invertebrates}

Densities of Heliocidaris erythrogramma were significantly lower in the SZ than at fished sites in 2004-2005 $\left(0.03 \pm 0.03\right.$ vs. $0.60 \pm 0.10$ ind $5 \mathrm{~m}^{-2}$; Table 3). Densities were again lower in the expanded surveys of 2005-2006 $(0.10 \pm 0.05$ vs. $0.38 \pm 0.07)$, but the difference was not statistically significant (Table 3). In both years, significant variation among sites was appar-

excluded. All 13 valid activations occurred during daylight hours, with the time to predation after deployment ranging between 0:12 and 18:33 (h:min). Only 1 timer was activated by predation within $30 \mathrm{~min}$ of tethering experiments being deployed, which suggested that predation was not closely linked to the presence of divers while deploying the timing devices.

Survival of tethered Centrostephanus tenuispinus was significantly lower in the SZ in 2004-2005 (those placed in the SZ were 5.1 times more likely to be eaten), but not in 2005-2006, when most individuals survived regardless of where they were placed. Sea urchin size was not a major influence in either year (Table 2). No predation was observed on any tethered Turbo spp.

To investigate whether western rock lobsters Panulirus cygnus could be responsible for predation of sea urchins, we conducted a laboratory experiment, presenting tethered Heliocidaris erythrogramma (range 49-71 mm test diameter) to individual P. cygnus ( $\mathrm{n}=8$, range 70-103 mm carapace length) kept in separate ent (Table 3). To test the possibility that the survey design used in 2004-2005 would have yielded the same result if used in 2005-2006, we also analysed the 2005-2006 data for the subset of sites also surveyed in 2004-2005; in this analysis there was a significant difference between the SZ and RZ $(F=7.98, \mathrm{p}=0.006)$. $H$. erythrogramma was observed at all 6 sites in the RZ in 2004-2005 (100\%) and at 18 of 24 sites in the fished zones in 2005-2006 (75\%) compared with 1 of 6 sites in the SZ in 2004-2005 (16\%) and 3 of 6 sites in the SZ in 2005-2006 (50\%).

Densities of Centrostephanus tenuispinus were higher in the SZ $(1.83 \pm 0.10)$ than at fished sites $(0.10 \pm$ 0.10 ) in 2004-2005, but the difference was not statistically significant (Table 3), and high densities were observed at only 2 of the 6 sites in the SZ. In the expanded surveys of 2005-2006, lower densities were recorded in the $\mathrm{SZ}(0.87 \pm 0.39)$ than at fished sites $(1.93 \pm 0.48)$; of the additional 18 sites surveyed outside the SZ, 6 hosted high densities of $C$. tenuispinus (Fig. 5). Similar to Heliocidaris erythrogramma, there

Table 3. Mixed effects ANOVAs on $\log (x+1)$-transformed counts of large herbivorous invertebrates, testing for differences in among reefs in zones designed to manage different types of fishing. Values in bold are significant at $\alpha=0.05$

\begin{tabular}{|c|c|c|c|c|c|c|c|c|c|c|}
\hline \multirow{2}{*}{ Source of variation } & \multirow[b]{2}{*}{ df } & \multicolumn{3}{|c|}{ Heliocidaris erythrogramma } & \multicolumn{3}{|c|}{ Centrostephanus tenuispinus } & \multicolumn{3}{|c|}{ Turbinid gastropods } \\
\hline & & MS & $F$ & $\mathrm{p}$ & MS & $F$ & $\mathrm{p}$ & MS & $F$ & $\mathrm{p}$ \\
\hline \multicolumn{11}{|l|}{ 2004-2005 } \\
\hline Fishing zone & 1 & 1.28 & 5.09 & 0.048 & 3.08 & 2.88 & 0.120 & 0.44 & 2.80 & 0.099 \\
\hline Area (Fishing zone) & & Pooled & Pooled & Pooled & & & & & & \\
\hline Site (Area, Fishing zone) & 10 & 0.25 & 2.11 & 0.042 & 1.07 & 3.64 & 0.001 & Pooled & & \\
\hline Residual & 48 & 0.12 & & & 0.29 & & & 0.16 & & \\
\hline \multicolumn{11}{|l|}{$2005-2006$} \\
\hline Fishing zone & 2 & 0.27 & 0.81 & 0.466 & 10.63 & 2.66 & 0.110 & 4.29 & 3.16 & 0.079 \\
\hline Area (Fishing zone) & 12 & 0.34 & 1.50 & 0.226 & 3.99 & 7.78 & $<0.001$ & 1.36 & 1.70 & 0.163 \\
\hline Site (Area, Fishing zone) & 15 & 0.22 & 1.88 & 0.031 & 0.51 & 2.35 & 0.005 & 0.78 & 2.80 & $<0.001$ \\
\hline Residual & 120 & 0.12 & & & 0.21 & & & 0.28 & & \\
\hline
\end{tabular}



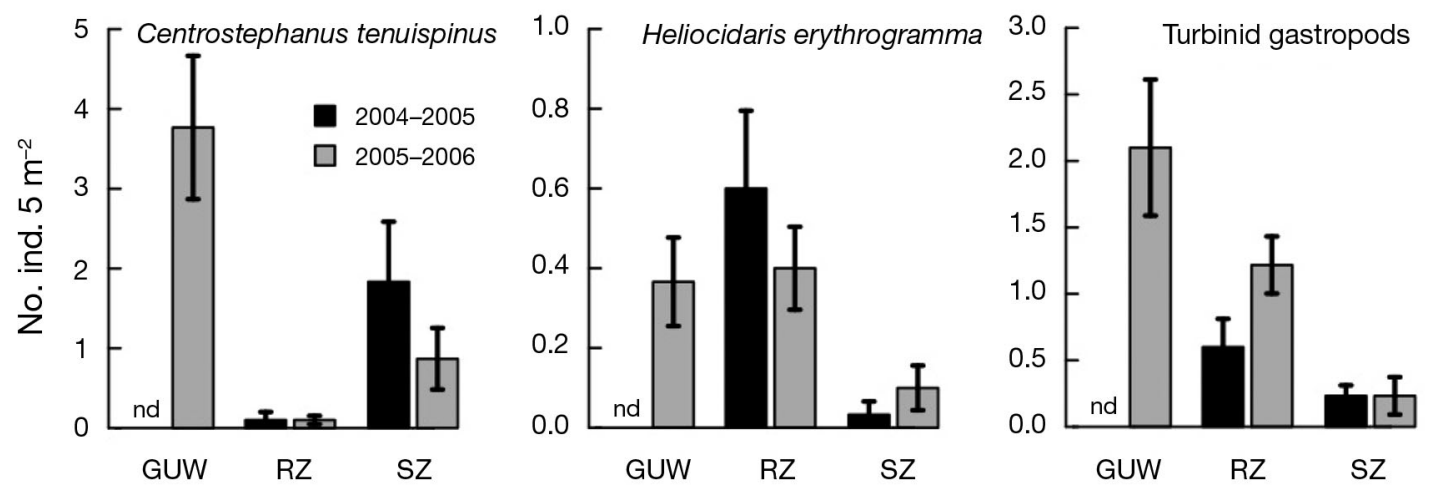

Fig. 5. Mean $( \pm \mathrm{SE})$ abundance of sea urchins (Centrostephanus tenuispinus and Heliocidaris erythrogramma) and turbinid gastropods seen on transects in each of the 3 fishing zones. For abbreviations see Fig. 3, legend

was considerable among-site variation in density (Table 3).

Densities of turbinid gastropods were lower in the SZ than at fished sites in 2004-2005 (0.23 \pm 0.07 vs. $0.60 \pm 0.21)$ and in the expanded surveys of 2005-2006 (0.23 \pm 0.14 vs. $1.66 \pm 0.28)$, but in neither year were the differences statistically significant (Table 3). Among-site variation in density of Turbo spp. was negligible in 2004-2005 but was large and significant in 2005-2006.

\section{Biomass of macroalgae}

The biomass of all macroalgae combined, and of the canopy-forming kelp Ecklonia radiata, was on average
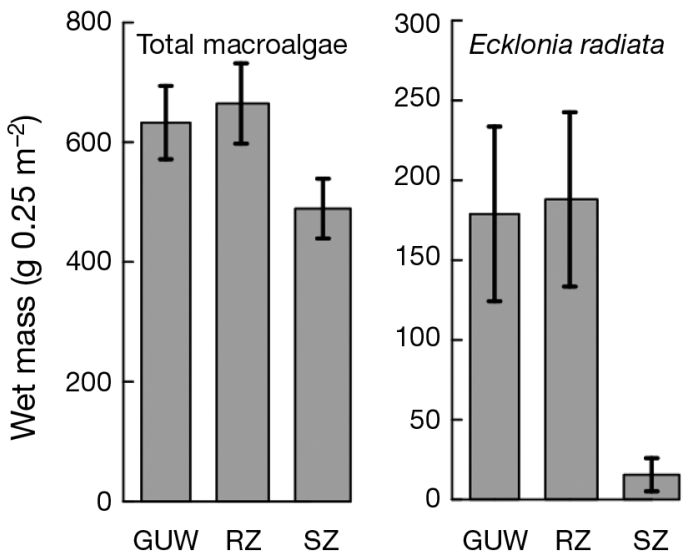

Fig. 6. Biomass of all macroalgae and of kelp (Ecklonia radiata) alone (mean $\pm \mathrm{SE}$ ) in each of the 3 fishing zones. For abbreviations see Fig. 3, legend. Macroalgal biomass was not sampled in 2004-2005
Table 4. Mixed effects ANOVAs on $\log (\mathrm{x}+1)$-transformed biomass of macroalgae, testing for differences in among reefs in zones designed to manage different types of fishing. Values in bold are significant at $\alpha=0.05$

\begin{tabular}{|lrrrrrrrrr|}
\hline Source of variation & \multicolumn{4}{c}{$\begin{array}{c}\text { Total } \\
\text { biomass }\end{array}$} & \multicolumn{4}{c}{$\begin{array}{c}\text { Ecklonia radiata } \\
\text { biomass }\end{array}$} \\
& df & MS & $F$ & p & MS & $F$ & p \\
\hline Fishing zone & 2 & 0.28 & 0.09 & 0.918 & 15.33 & 0.70 & 0.517 \\
Area (Fishing zone) & 12 & 3.24 & 2.10 & 0.088 & 22.00 & 6.79 & $<\mathbf{0 . 0 0 1}$ \\
Site (Area, Fishing zone) & 15 & 1.54 & 4.03 & $\mathbf{0 . 0 0 1}$ & 3.24 & 0.61 & 0.865 \\
Residual & 120 & 0.38 & & & 5.34 & & \\
& & & & & & & & &
\end{tabular}

lower in the SZ (Fig. 6), but there was considerable variability at smaller spatial scales (among sites for total macroalgae, and among areas for E. radiata), and there were no statistically significant differences between management zones (Table 4). Four sites in the SZ and 8 sites in the fished zones did not have any $E$. radiata, and every site yielded at least one quadrat with no E. radiata.

\section{DISCUSSION}

The abundance of predatory fish and the intensity of predation on one species of tethered sea urchin (Heliocidaris erythrogramma) were higher in the SZ than at fished sites. In addition, the densities of $H$. erythrogramma were lower in the SZ in each year, although the difference was not statistically significant in 2005-2006. These patterns are consistent with an indirect effect of fishing extending to one of the 3 species of potential prey we examined ( $H$. erythrogramma). However, predation on tethered individuals, and density of Centrostephanus tenuispinus and Turbo spp., did not follow the same pattern (although there was higher predation on $C$. tenuispinus in one year and a trend for lower densities of Turbo spp. in the SZ), sug- 
gesting that the influence of predators was not ubiquitous on all potential species of prey. In addition, the biomass of macroalgae did not show any patterns that suggested that indirect effects of fishing extended to the lowest trophic level.

Because the present study, like others, relies on spatial contrasts for inferences about the effects of fishing, we rely on the assumption that differences are due to regulations that restrict fishing, and were not present prior to the establishment of the management zones. Although we do not have data to test this assumption, there is no evidence that sanctuary zones in temperate Australia (including Rottnest Island) have been placed in areas with higher abundances of fish (indeed, there is evidence to the contrary: Edgar et al. 2009). Inferences about the effects of fishing that are derived from spatial contrasts are therefore likely to be robust (see also Russ et al. 2005).

\section{Density of predatory fish}

Predatory fish were more abundant inside the SZ than at fished sites. This is consistent with the numerous studies that have reported higher abundances of fish inside MPAs (see Halpern 2003, Palumbi 2004 for reviews). Predatory fish inhabiting temperate reefs in particular show strong positive responses to protection from fishing (e.g. Willis et al. 2003, Guidetti 2006, Barrett et al. 2007).

Although many studies have assessed differences in the abundance of fish, few have incorporated an assessment of partially protected areas such as RZ (where commercial fishing is excluded) at Rottnest Island. We found no statistically significant differences in density of predatory fish between the RZ and GUW. Similarly, in New Zealand, Denny \& Babcock (2004) found that partial protection (exclusion of commercial fishing and gear restrictions for recreational fishing) had no positive effect on abundance of temperate reef fishes, and in some cases had a negative effect, perhaps increasing fishing pressure by attracting people to the area.

\section{Predation on tethered invertebrates}

At fished sites, there was lower mortality of Heliocidaris erythrogramma in both years and of Centrostephanus tenuispinus in 2004-2005. Other studies quantifying relative predation rates have also found that higher abundances of predators in temperate reef MPAs resulted in increased predation on sea urchins (Shears \& Babcock 2002, Hereu et al. 2005, Guidetti 2006, Pederson \& Johnson 2006).
Several studies have found that larger sea urchins may also have fewer predators (Sala 2004, Guidetti et al. 2005), but we generally found little effect of sea urchin diameter on predation and, where present (i.e. predation on Heliocidaris erythrogramma in 2005), larger individuals in our study were more susceptible to predation-a pattern that might indicate that smaller urchins were able to enter small crevices that were inaccessible to larger urchins. Only 1 species of predatory fish (Achoerodus gouldii) was observed to prey successfully on Centrostephanus tenuispinus whereas 5 species preyed successfully on $H$. erythrogramma. Adult C. tenuispinus have larger tests and longer spines than $H$. erythrogramma; these differences in morphology are probably responsible for the difference in predation on the 2 species of sea urchins (e.g. Guidetti \& Mori 2005).

Other studies elsewhere in southern Australia have found that rock lobsters (although a different species, Jasus edwardsii) are important predators of Heliocidaris erythrogramma (Pederson \& Johnson 2006) and another species of Centrostephanus (C. rodgersii; Ling et al. 2009). However, predation on $H$. erythrogramma tethered to timing devices occurred only during daylight hours, suggesting that diurnal predators were the most important predators of $H$. erythrogramma. The western rock lobster Panilurus cygnus mainly forages at night (MacArthur et al. 2008), and so predation by lobsters is unlikely, despite the presence of greater densities and larger sizes of lobsters in the SZ (Babcock et al. 2007). The diurnal pattern of predation indicated by the timers, combined with the lack of predation on sea urchins by P. cygnus in the laboratory, strengthens inferences that predatory fish were primarily responsible for mortality of tethered sea urchins.

During tethering experiments, no predation on Turbo spp. was observed. Although efforts were made to include a wide size range of Turbo spp. (11-55 mm), perhaps even small individuals are too large for the main predators, as observed for the trochid gastropod Tectus pyramis (Scheibling \& Hatcher 1997). Other studies have also found low predation rates on gastropods (McClanahan 1992, Valentine et al. 2008), and thick-shelled gastropods might be well protected from most predators. Indeed, predation rates can vary substantially between gastropods with different shell thicknesses (Tuya et al. 2010). The lack of predation on tethered Turbo spp. could also be due to an insufficient experimental duration, as experiment duration can be a strong influence (Minello 1993, Haywood \& Pendrey 1996). For example, Scheibling \& Hatcher (1997) found that large Trochus histrio were able to survive for several days whereas small individuals were all preyed upon within $6 \mathrm{~h}$. The low rates of predation we 
observed combined with the small (and non-significant) differences in density between the SZ and fished areas suggest that, as for $C$. tenuispinus, predation is not a strong control on the density of Turbo spp., at least on the size ranges we observed.

\section{Density of invertebrates}

Although many studies have found that the abundance of predators has direct negative effects on abundances of large invertebrates that are their prey, others have concluded that, in some circumstances, density of sea urchins is unaffected by differences in predator density (Guidetti et al. 2005, Shears et al. 2008, Foster \& Schiel 2010). In the present study, mean densities of Heliocidaris erythrogramma were lower in the SZ than at fished sites in both years, but the difference was statistically significant only during the first survey. Analyses of the subset of sites from the second survey that were also included in the first survey yielded a significant difference. The presence of lower densities in the sanctuary in both years and the observation that $H$. erythrogramma were present at fewer sites within the sanctuary support the inference that the higher rates of predation do influence the abundance of $H$. erythrogramma.

Lower densities were also recorded in the SZ for turbinid gastropods (although patterns were not statistically significant). However, even at fished sites densities of Turbo spp. were generally low, and we did not record any predation on tethered individuals, so we cannot unequivocally conclude that any differences were due to predators.

Among the most important controls on the abundance of sea urchins is recruitment of juveniles (Sala et al. 1998). A study at Rottnest Island found that recruitment of Heliocidaris erythrogramma was higher at a site in the SZ than at a similar site in the RZ (StuartAndrews 2005), but did not record any recruitment of Centrostephanus tenuispinus. Prince (1995) also found low recruitment of Turbo intercostalis at Rottnest Island. Low recruitment could be a contributing factor to the low overall densities of $C$. tenuispinus and Turbo spp., but recruitment of $H$. erythrogramma is unlikely to be limiting, suggesting that post-settlement processes might be more important.

Predation is only one of the processes that can cause post-settlement mortality, but our observations showed that Heliocidaris erythrogramma was susceptible to more species of predators than Centrostephanus tenuispinus and Turbo spp., was predated at higher rates and had lower densities in the $\mathrm{SZ}$, so it seems likely that predation is an important control on its abundance. Nevertheless, rates of predation on teth- ered $H$. erythrogramma in our study were, on average, greater than $50 \%$ in both the SZ and fished zones. We note that these rates of predation on $H$. erythrogramma are somewhat higher than those observed by Pederson \& Johnson (2006) in Tasmania; although it is not possible to draw strong inferences about biogeographic patterns in predation rates from the limited number of studies that have been conducted, it is plausible that the generally low abundances of sea urchins recorded in southern and western Australia (Fowler-Walker \& Connell 2002, Vanderklift \& Kendrick 2004) might be due to biogeographic patterns in rates of predation.

\section{Biomass of macroalgae}

We found no evidence for indirect effects of fishing on the biomass of macroalgae (there were no significant differences among management zones, although biomass varied significantly among areas and sites). The lack of effects is likely to be due, in part, to the low densities of large herbivorous invertebrates. Densities of sea urchins were much lower than those reported in areas susceptible to barren formation. For example, in New Zealand, densities of Evechinus chloroticus less than $6 \mathrm{~m}^{-2}$ did not induce barren formation (Ayling 1981) and in eastern Australia, densities of Centrostephanus rodgersii ranged from $2-10 \mathrm{~m}^{-2}$ in barrens (Ling et al. 2009). The lack of effects is also likely in part due to the feeding behaviour of Heliocidaris erythrogramma, which mainly eats drift algae (Vanderklift \& Kendrick 2005, Vanderklift \& Wernberg 2008). Even high densities of $H$. erythrogramma might not exert a strong influence on the biomass of macroalgae, as experimentally elevated densities at a nearby reef did not result in changes to biomass of macroalgae (Vanderklift \& Kendrick 2005). This is consistent with patterns observed elsewhere in Australia, where strong effects of grazing by $H$. erythrogramma have only been observed in areas that do not experience strong waves (Wright et al. 2005, Ling et al. 2010).

\section{Conclusions}

Our results are consistent with the prediction that fishing reduces the abundance of predatory fish at Rottnest Island, and that this in turn reduces predation rates on sea urchins, thus indirectly influencing the abundance of one species of sea urchin (Heliocidaris erythrogramma). However, we found no evidence that the indirect effects of fishing extend to other large mobile invertebrates, or to macroalgae. This result adds to the evidence that trophic cascades extending from predators to dominant autotrophs (and resulting 
in alternate ecosystem states) are not ubiquitously present in temperate reef ecosystems; rather, they occur only in limited circumstances. Micheli et al. (2005) found that indirect effects of fishing in Mediterranean reserves were likely to occur only at locations protected from waves. In New Zealand, Shears et al. (2008) also found that indirect effects of fishing did not occur at locations that were exposed to waves or where there was a high cover of sediment on rocky surfaces. Cardona et al. (2007) similarly reported a lack of indirect effects of fishing in the Mediterranean, due to low recruitment. It seems that many factors can act to reduce the likelihood of trophic cascades in temperate reef ecosystems; clearly, the presence of trophic cascades is context dependent. A challenge for ecologists is to identify the contexts in which trophic cascades are likely to occur. Our results suggest that trophic cascades involving sea urchins are not a major feature of southern and western Australian coasts, where herbivory does not have a major influence on patterns in the abundance of kelp.

Acknowledgements. We thank the Rottnest Island Authority for logistical support and research permits; R. Black, R. Babcock and G. Kendrick for advice; numerous volunteers for assistance in the field; and F. Tuya for comments on the manuscript. The experiments complied with the laws of Australia. This research was partially supported by the Strategic Research Fund for the Marine Environment, the Australian Research Council and the Western Australian Marine Science Institution.

\section{LITERATURE CITED}

Ayling AM (1981) The role of biological disturbance in temperate subtidal encrusting communities. Ecology 62: 830-847

Babcock RC, Kelly S, Shears NT, Walker JW, Willis TJ (1999) Changes in community structure in temperate marine reserves. Mar Ecol Prog Ser 189:125-134

Babcock RC, Phillips JC, Lourey M, Clapin G (2007) Increased density, biomass and egg production in an unfished population of western rock lobster (Panulirus cygnus) at Rottnest Island, Western Australia. Mar Freshw Res 58:286-292

Barrett NS, Edgar GJ, Buxton CD, Haddon M (2007) Changes in fish assemblages following 10 years of protection in Tasmanian marine protected areas. J Exp Mar Biol Ecol 345:141-157

- Bascompte J, Melian CJ, Sala E (2005) Interaction strength combinations and the overfishing of a marine food web. Proc Natl Acad Sci USA 102:5443-5447

Cardona L, Sales M, López D (2007) Changes in fish abundance do not cascade to sea urchins and erect algae in one of the most oligotrophic parts of the Mediterranean. Estuar Coast Shelf Sci 72:273-282

Connell SD (2007) Subtidal temperate rocky habitats: habitat heterogeneity at local to continental scales. In: Connell SD, Gillanders BM (eds) Marine ecology. Oxford University Press, South Melbourne, p. 378-401
Connell SD, Irving AD (2008) Integrating ecology with biogeography using landscape characteristics: a case study of subtidal habitat across continental Australia. J Biogeogr 35:1608-1621

Connell SD, Irving AD (2009) The subtidal ecology of rocky coasts: local-regional-biogeographical patterns and their experimental analysis. In: Witman JD, Roy K (eds) Marine macroecology. University of Chicago Press, Chicago, IL, p. 392-417

Dayton PK, Tegner MJ, Edwards PB, Riser KL (1998) Sliding baselines, ghosts and reduced expectations in kelp forest communities. Ecol Appl 8:309-322

Denny CM, Babcock RC (2004) Do partial marine reserves protect reef fish assemblages? Biol Conserv 116:119-129

Edgar GJ, Barrett NS, Stuart-Smith RD (2009) Exploited reefs protected from fishing transform over decades into conservation features otherwise absent from seascapes. Ecol Appl 19:1967-1974

Estes JA, Danner EM, Doak DF, Konar B and others (2004) Complex trophic interactions in kelp forest ecosystems. Bull Mar Sci 74:621-638

Foster MS, Schiel DR (2010) Loss of predators and the collapse of southern California kelp forests (?): alternatives, explanations and generalizations. J Exp Mar Biol Ecol 393: $59-70$

Fowler-Walker M, Connell SD (2002) Opposing states of subtidal habitat across temperate Australia: consistency and predictability in kelp canopy-benthic associations. Mar Ecol Prog Ser 240:49-56

- Fretwell SD (1987) Food chain dynamics: The central theory of ecology? Oikos 50:291-301

> Guidetti P (2006) Marine reserves reestablish lost predatory interactions and cause community changes in rocky reefs. Ecol Appl 16:963-976

Guidetti P, Mori M (2005) Morpho-functional defenses of Mediterranean sea urchins, Paracentrotus lividus and Arbacia lixula, against fish predators. Mar Biol 147: 797-802

> Guidetti P, Bussotti S, Boero F (2005) Evaluating the effects of protection on fish predators and sea urchins in shallow artificial rocky habitats: a case study in the northern Adriatic Sea. Mar Environ Res 59:333-348

Hairston NG, Smith FE, Slobodkin LB (1960) Community structure, population control and competition. Am Nat 94: 421-425

Halpern BS (2003) The impact of marine reserves: do reserves work and does reserve size matter? Ecol Appl (Suppl)13: $117-137$

Haywood MDE, Pendrey RC (1996) A new design for a submersible chronographic tethering device to record predation in subtidal habitats. Mar Ecol Prog Ser 143:307-312

> Hereu B, Zabala M, Linares C (2005) The effects of predator abundance and habitat structural complexity on survival of juvenile sea urchins. Mar Biol 146:293-299

Hosmer DW, Lemeshow S (2000) Applied logistic regression. Wiley, New York

Kleczkowski M, Babcock RC, Clapin G (2008) Density and size of reef fishes in and around a temperate marine reserve. Mar Freshw Res 59:165-176

Ling SD, Johnson CR, Frusher SD, Ridgeway KR (2009) Overfishing reduces resilience of kelp beds to climate-driven catastrophic phase shift. Proc Natl Acad Sci USA 106: 22341-22345

> Ling SD, Ibbott S, Sanderson JC (2010) Recovery of canopyforming macroalgae following removal of the enigmatic grazing sea urchin Heliocidaris erythrogramma. J Exp Mar Biol Ecol 395:135-146 
MacArthur LD, Hyndes GA, Babcock RC, Vanderklift MA (2008) Nocturnally active western rock lobsters Panulirus cygnus forage close to shallow coastal reefs. Aquat Biol 4: 201-210

McClanahan TR (1992) Epibenthic gastropods of the Middle Florida Keys: the role of habitat and environmental stress on assemblage composition. J Exp Mar Biol Ecol 160: 169-190

> McClanahan TR, Muthiga NA, Kamukuru AT, Machano H, Kiambo RW (1999) The effects of marine parks and fishing on coral reefs of northern Tanzania. Biol Conserv 89: 161-182

Micheli F, Benedetti-Cecchi L, Gambaccini S, Bertocci I, Borsini C, Osio GC, Roman F (2005) Cascading human impacts, marine protected areas, and the structure of Mediterranean reef assemblages. Ecol Monogr 75:81-102

Minello TJ (1993) Chronographic tethering: a technique for measuring prey survival time and testing predation pressure in aquatic habitats. Mar Ecol Prog Ser 101:99-104

Oliver M, Stewart R, Mills D, MacDiarmid A, Gardner C (2005) Stock enhancement of rock lobsters (Jasus edwardsii): timing of predation on naive juvenile lobsters immediately after release. NZ J Mar Freshw Res 39:391-397

Paine RT (1980) Food webs: linkage, interaction strength and community infrastructure. J Anim Ecol 49:667-685

Palumbi SR (2004) Marine reserves and ocean neighbourhoods: the spatial scale of marine populations and their management. Annu Rev Environ Resour 29:31-68

Pederson HG, Johnson CR (2006) Predation of the sea urchin Heliocidaris erythrogramma by rock lobsters (Jasus edwardii) in no-take marine reserves. J Exp Mar Biol Ecol 336:120-134

Peterson CH, Black R (1994) An experimentalist's challenge: when artifacts of intervention interact with treatments. Mar Ecol Prog Ser 111:289-297

Polis GA (1994) Food webs, trophic cascades and community structure. Aust J Ecol 19:121-136

Prince J (1995) Limited effects of the sea urchin Echinometra mathaei (de Blainville) on the recruitment of benthic algae and macroinvertebrates into intertidal rock platforms at Rottnest Island, Western Australia. J Exp Mar Biol Ecol 186:237-258

Russ GR, Stockwell B, Alcala AC (2005) Inferring versus measuring rates of recovery in no-take marine reserves. Mar Ecol Prog Ser 292:1-12

Sala E (2004) The past and present topology and structure of Mediterranean subtidal rocky-shore food webs. Ecosystems 7:333-340

Sala E, Boudouresque CF, Harmelin-Vivien M (1998) Fishing, trophic cascades, and the structure of algal assemblages: evaluation of an old but untested paradigm. Oikos 82: 425-439

Editorial responsibility: Kenneth Heck Jr., Dauphin Island, Alabama, USA
Scheibling RE, Hatcher BG (1997) Microhabitat refuges and risk of predation for two species of trochid gastropod (Trochus histrio and Tectus pyramus) at the Houtman Abrolhos Islands, Western Australia. In: Wells FE (ed) The marine flora and fauna of the Houtman Abrolhos Islands, Western Australia, Vol. 1. Western Australian Museum, Perth, p. 161-176

Shears NT, Babcock RC (2002) Marine reserves demonstrate top-down control of community structure on temperate reefs. Oecologia 132:131-142

Shears NT, Babcock RC (2003) Continuing trophic cascade effects after 25 years of no-take marine reserve protection. Mar Ecol Prog Ser 246:1-16

Shears NT, Babcock RC, Salomon AK (2008) Context-dependent effects of fishing: variation in trophic cascades across environmental gradients. Ecol Appl 18:1860-1873

Steneck RS, Graham MH, Bourque BJ, Corbett D, Erlandson JM, Estes JA, Tegner MJ (2002) Kelp forest ecosystems: biodiversity, stability, resilience and future. Environ Conserv 29:436-459

Stuart-Andrews C (2005) Spatial and temporal patterns of recruitment of Heliocidaris erythrogramma (Valenciennes, 1846) on the central West Australian coast. Honours thesis, The University of Western Australia, Crawley

> Tuya F, Vanderklift MA, Hyndes GA, Wernberg T, Thomsen MS, Hanson C (2010) Proximity to rocky reefs alters the balance between positive and negative effects on seagrass fauna. Mar Ecol Prog Ser 405:175-186

- Valentine JF, Heck KL Jr, Blackmon D, Goecker ME and others (2008) Exploited species impacts on trophic linkages along reef-seagrass interfaces in the Florida Keys. Ecol Appl 18:1501-1515

Vanderklift MA, Kendrick GA (2004) Variation in abundances of herbivorous invertebrates in temperate subtidal rocky reef habitats. Mar Freshw Res 55:93-103

Vanderklift MA, Kendrick GA (2005) Contrasting influences of sea urchins on attached and drift macroalgae. Mar Ecol Prog Ser 299:101-110

- Vanderklift MA, Wernberg T (2008) Detached kelps from distant sources are a food subsidy for sea urchins. Oecologia 157:327-335

Willis TJ, Millar RB, Babcock RC (2003) Protection of exploited fish in temperate regions: high density and biomass of snapper Pagrus auratus (Sparidae) in northern New Zealand marine reserves. J Appl Ecol 40:214-227

Winer BJ (1971) Statistical principles in experimental design, McGraw-Hill Kogakusha Ltd

> Wright JT, Dworjanyn SA, Rogers CN, Steinberg PD, Williamson JE, Poore AGB (2005) Density-dependent sea urchin grazing: differential removal of species, changes in community composition and alternative community states. Mar Ecol Prog Ser 298:143-156

Submitted: April 1, 2010; Accepted: March 31, 2011

Proofs received from author(s): June 9, 2011 